\title{
Role of sleep-disordered breathing and sleep-wake disturbances for stroke and stroke recovery OPEN
}

Dirk M. Hermann, MD

Claudio L. Bassetti, MD

Correspondence to Prof. Dr. med. Hermann: dirk.hermann@uk-essen.de or Prof. Dr. med. Bassetti: claudio.bassetti@insel.ch

\section{ABSTRACT}

Background: Sleep-disordered breathing (SDB) and sleep-wake disturbances (SWD) are highly prevalent in stroke patients. Recent studies suggest that they represent both a risk factor and a consequence of stroke and affect stroke recovery, outcome, and recurrence.

Methods: Review of literature.

Results: Several studies have proven SDB to represent an independent risk factor for stroke. Sleep studies in TIA and stroke patients are recommended in view of the very high prevalence (>50\%) of SDB (Class llb, level of evidence B). Treatment of obstructive SDB with continuous positive airway pressure is recommended given the strength of the increasing evidence in support of a positive effect on outcome (Class Illb, level of evidence B). Oxygen, biphasic positive airway pressure, and adaptive servoventilation may be considered in patients with central SDB. Recently, both reduced and increased sleep duration, as well as hypersomnia, insomnia, and restless legs syndrome (RLS), were also suggested to increase stroke risk. Mainly experimental studies found that SWD may in addition impair neuroplasticity processes and functional stroke recovery. Treatment of SWD with hypnotics and sedative antidepressants (insomnia), activating antidepressants or stimulants (hypersomnia), dopaminergic drugs (RLS), and clonazepam (parasomnias) are based on single case observations and should be used with caution.

Conclusions: SDB and SWD increase the risk of stroke in the general population and affect shortand long-term stroke recovery and outcome. Current knowledge supports the systematic implementation of clinical procedures for the diagnosis and treatment of poststroke SDB and SWD on stroke units. Neurology ${ }^{\circledR} 2016 ; 87: 1407-1416$

\section{GLOSSARY}

$\mathbf{A H I}=$ apnea-hypopnea index; BMI = body mass index; $\mathbf{C H D}=$ coronary heart disease; $\mathbf{C l}=$ confidence interval; $\mathbf{C P A P}=$ continuous positive airway pressure; CSA = central sleep apnea; CSB = Cheyne-Stokes breathing; EDS = excessive daytime sleepiness; HR = hazard ratio; NREM = non-REM; OR = odds ratio; OSA = obstructive sleep apnea; PLMS = periodic limb movements during sleep; RBD = REM sleep behavior disorder; RLS = restless legs syndrome; SDB = sleep-disordered breathing; SWA = slow wave activity; SWD = sleep-wake disturbances.

Sleep-disordered breathing (SDB) and sleep-wake disturbances (SWD) are highly prevalent in neurologic diseases, influencing their incidence, course, and outcome, which has been linked to sleep having neurorestorative functions. ${ }^{1,2}$ In this review, we review the data suggesting that sleep-wake disorders represent both a risk factor and a consequence of stroke that modulate stroke recovery and outcome. For this purpose, we performed a comprehensive PubMed search in December 2015 with the terms sleep or sleepiness or insomnia or hypersomnia or restless legs syndrome or periodic limb movements during sleep and stroke that achieved 2,691 hits. Articles were selected based on their contribution to our current understanding of sleep/stroke links. Systematic reviews and meta-analyses were extensively used to evaluate research evidence. Diagnostic challenges and treatment recommendations are presented.

From the Department of Neurology (D.M.H.), University Hospital Essen, Germany; and Department of Neurology (C.L.B.), University Hospital Berne, Switzerland.

Go to Neurology.org for full disclosures. Funding information and disclosures deemed relevant by the authors, if any, are provided at the end of the article. The Article Processing Charge was paid by the authors.

This is an open access article distributed under the terms of the Creative Commons Attribution-NonCommercial-NoDerivatives License 4.0 (CC BY-NC-ND), which permits downloading and sharing the work provided it is properly cited. The work cannot be changed in any way or used commercially. 
DISTURBED SLEEP IN STROKE PATIENTS Sleep-

disordered breathing. In a meta-analysis of 29 studies with 2,343 ischemic or hemorrhagic stroke or TIA patients, $72 \%, 63 \%$, or $38 \%$ revealed SDB defined by an apnea-hypopnea index (AHI) $>5 / \mathrm{h},>10 / \mathrm{h}$, or $>20 /$ h. $^{3}$ SDB was most severe in acute stroke and improved during stroke recovery. Fifty-three percent of

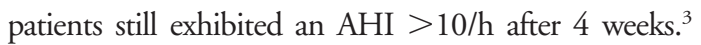
SDB was similarly prevalent in stroke and TIA, ${ }^{2}$ indicating that SDB mostly represents a preexisting condition. In a cross-sectional study on 335 acute stroke or TIA patients, SDB was associated with wakeup stroke, when accompanied by cardiac right-to-left shunts, ${ }^{4}$ indicating that SDB may provoke paradoxical embolism. Initial studies found no link between SDB and stroke topography. Population-based ${ }^{5}$ and clinical ${ }^{6}$ cohorts recently noted an association of SDB with brainstem stroke, suggesting that lower cranial nerve dysfunction aggravates SDB. The most common form of SDB is obstructive sleep apnea (OSA), which is caused by cessation of nasal flow due to upper airway collapse. Not rarely, stroke patients reveal combinations of OSA and central types of SDB; that is, central sleep apnea (CSA) and Cheyne-Stokes breathing (CSB)., 2,7

CSA is characterized by cyclic fluctuations in breathing drive and hyperpneas alternating with apneas or hypopneas. CSA/CSB was first described in bilateral stroke associated with disturbed consciousness or heart failure. Heart failure is associated with nocturnal rostral fluid shifts decreasing leg volume and increasing neck circumference, which predisposes to upper airway collapse. ${ }^{8}$ More recently, CSB during sleep was found in unilateral stroke with preserved consciousness without overt heart failure. CSA/CSB in acute stroke was linked to occult cardiac dysfunction $^{9}$ or disruption of the central autonomic networks. ${ }^{2}$ CSA/CSB improves in the subacute stroke phase. In chronic stroke, CSA/CSB is strongly associated with heart failure. ${ }^{9}$

Hypersomnia/excessive sleep/excessive daytime sleepiness (EDS). Hypersomnia, i.e., increased sleep, is mostly found after subcortical and pontomesencephalic stroke. In 285 consecutive patients evaluated after $21 \pm 18$ months, hypersomnia $(27 \%$ of patients with sleep needs $\geq 10 \mathrm{~h} / \mathrm{d}$ ), EDS (28\% with Epworth Sleepiness Scale score $\geq 10$ ) and fatigue ( $46 \%$ with Fatigue Severity Scale score $\geq 4.0$ ) were frequent. ${ }^{2}$ Although hypersomnia improves during the first months poststroke, fatigue can persist for years. The most dramatic form of poststroke hypersomnia is noted after paramedian thalamic stroke. Initially, patients exhibit severe hypersomnia and sleep-like behavior during up to $20 \mathrm{~h} / \mathrm{d}$, associated with attention, cognition, and memory deficits. ${ }^{10,11}$ Hypersomnia improves within months, whereas cognitive deficits often persist, particularly after left-sided and bilateral stroke. ${ }^{11}$ Patients with bilateral stroke may report increased sleep needs for years.

Insomnia/reduced sleep. Insomnia, i.e., difficulty in falling and staying asleep, is highly prevalent in stroke patients. During the first months poststroke, insomnia prevalence may be as high as $\sim 50 \%$. $^{2}$ One third of insomnias appear de novo; two thirds of patients have insomnia already before stroke. Poststroke insomnia often results from environmental factors (light, noise on stroke units) or comorbidities (SDB, depression, pain). Less commonly, insomnia may be directly related to brain damage. Near-complete loss of sleep was reported after pontomesencephalic stroke. ${ }^{2}$ In paramedian thalamic stroke, insomnia may reflect the absence of sleep spindles. ${ }^{11}$ In military veterans with penetrating brain injury, insomnia was associated with left dorsomedial prefrontal cortex damage. ${ }^{12}$

Restless legs syndrome (RLS)/periodic limb movements during sleep (PLMS). In 2 series of 96 or 137 patients examined within 15 days or at 1 month poststroke, $12 \%$ or $13 \%$ fulfilled RLS criteria, i.e., urge for limb movements that improves with activity and worsens in the evenings and nights and at rest. ${ }^{13,14}$ Two thirds of patients had bilateral RLS symptoms; one third had unilateral symptoms contralateral to the stroke. ${ }^{13}$ RLS was frequently accompanied by PLMS, i.e., involuntary periodic limb movements during non-REM (NREM) sleep. Patients exhibiting RLS exhibited a higher neck circumference and higher diabetes prevalence than patients without RLS. ${ }^{14}$ Sleep quality was reduced in these patients. PLMS are even more prevalent than RLS in stroke patients. In a case-control study of 35 patients with acute supratentorial ischemic stroke, a PLMS index $>5 / \mathrm{h}$ was found in $77 \%$ of stroke patients but only $29 \%$ of age- and sexmatched controls. ${ }^{15}$ PLMS were contralateral to the stroke in $70 \%$ and bilateral in $30 \%$.

REM sleep behavior disorder (RBD). In RBD, patients act out dreams, exhibiting loss of atonia and increased phasic muscle activity during REM sleep. Following early RBD observations in patients with brainstem infarcts, ${ }^{2}$ a recent assessment on 119 ischemic stroke patients estimated the RBD prevalence as $\sim 11 \%$. $^{16}$ Forty-six percent of patients with RBD had brainstem infarcts. ${ }^{16}$

\section{DISTURBED SLEEP AS STROKE RISK FACTOR}

Sleep-disordered breathing. Following a seminal study on 1,022 patients admitted to a sleep laboratory, which reported an association of SDB defined as AHI $\geq 5 / \mathrm{h}$ with incident stroke, TIA, and death over 6 years follow-up after adjustment for vascular risk factors, ${ }^{17}$ 4 population-based studies evaluated the predictive value of SDB for stroke risk: 
1. The Wisconsin sleep cohort study included 1,475 participants. ${ }^{18}$ SDB defined by AHI $\geq 20 / \mathrm{h}$ was associated in a cross-sectional analysis with history of stroke after adjustment for age, sex, and vascular risk factors (odds ratio [OR] 4.33; confidence interval [CI] 1.32-14.24). In a longitudinal analysis including 1,189 participants, 22 incident first-ever strokes were noted over 4 years. SDB predicted stroke in a univariate regression. After adjustment for age, sex, and body mass index (BMI), this association was no longer significant.

2. In the Vitoria Sleep Project, 394 noninstitutionalized stroke-free participants $>70$ years were followed up over 6 years (incident 20 strokes). ${ }^{19} \mathrm{SDB}$ defined by AHI $>30 / \mathrm{h}$ predicted stroke in a regression adjusted for sex (hazard ratio [HR] 2.52; CI 1.04-6.01). Due to limited statistical power, age and vascular risk factors could not be adjusted for.

3. The Sleep Heart Health Study was a populationbased cohort of 5,422 participants $\geq 40$ years followed up over 8.7 years. ${ }^{20} \mathrm{~A}$ total of 193 strokes occurred. OSA predicted ischemic stroke in multivariable regressions adjusted for age, sex, and vascular risk factors in men (HR [4th vs 1st AHI quartile] 2.86; CI 1.10-7.39) but not in women (HR 1.21; CI 0.65-2.24).

4. In a nationwide survey among 4.5 million Danish citizens, 33,274 participants developed sleep apnea over 11 years (mean age 53 years; 79\% men), of whom $44 \%$ received persistent continuous positive airway pressure (CPAP) therapy. ${ }^{21} \mathrm{~A}$ total of 150,294 ischemic strokes occurred. Sleep apnea predicted ischemic stroke after adjustment for age, sex, and vascular risk factors (HR 1.23; CI $1.11-1.36)$. This effect was specifically noted in participants $<50$ years (HR 1.80; CI 1.36-2.39).

A meta-analysis of prospective clinical and population-based studies concluded that $\mathrm{SDB}$ is an independent stroke predictor (OR 2.24; CI 1.573.19). ${ }^{22}$ Stroke risk increased with AHI. ${ }^{22}$ The metaanalysis stated that evidence was sparse in women. Most recently, a Taiwanese group evaluated sexrelated consequences of SDB in a large cohort of 29,961 participants with SDB who were compared with 119,844 age- and sex-matched controls without SDB. ${ }^{23}$ Over a follow-up of up to 14 years, stroke incidence was increased in both sexes, notably more strongly in women than men (HR 1.44 [CI 1.201.72] and HR 1.21 [CI 1.01-1.24], respectively, after adjustment for age and vascular risk factors). Interestingly, stroke incidence was increased most strongly in young women $\leq 35$ years (HR 4.90 [CI 1.93-12.40]).

The mechanisms underlying the elevated stroke risk in SDB patients have been summarized previously. ${ }^{24}$
Recurrent hypoxia in OSA is accompanied by intrathoracic pressure changes, sympathetic activation, and blood pressure swings, which via oxidative stress, endothelial dysfunction, and inflammation predispose to drug-resistant arterial hypertension, atherosclerosis, cardiac arrhythmia, hypercoagulation, heart failure, and paradoxical embolisms. CPAP therapy attenuates these consequences.

Hypersomnia/excessive sleep/EDS. A meta-analysis of 11 community-representative studies with 559,252 participants and 11,695 stroke events revealed that long sleep, mostly defined as $\geq 8-9$ hours sleep/ night in questionnaires, is an independent predictor of incident stroke after adjustment for age, sex, vascular risk factors, and comorbidities (HR 1.45; CI $1.30-1.62) .^{25}$ In 2 population-based studies involving 9,095 participants who were followed up over 5.1 years each (in total 208 incident strokes), significant (Epworth Sleepiness Scale $\geq 10 / 24$ ) or frequent EDS predicted stroke after adjustment for age, sex, vascular risk factors, and comorbidities (HR 3.00; CI 1.57-5.73, and HR 2.10; CI 1.13-3.89, respectively). ${ }^{26,27}$ In a cross-sectional analysis within one of these studies, which included 1,244 stroke-free participants receiving MRI, long sleep was associated with subcortical white matter hyperintensities, ${ }^{28}$ suggesting that excessive sleep may result from cerebral small vessel disease, reflecting markers of subclinical atherosclerosis.

Insomnia/reduced sleep. After earlier inconsistent studies, a recent meta-analysis found that short sleep, mostly defined as $\leq 5-6$ hours sleep/night in questionnaires, is an independent predictor of incident stroke after adjustment for age, sex, vascular risk factors, and comorbidities, albeit with lower HR than long sleep (1.15; CI 1.07-1.24). ${ }^{25}$ Stroke risk might depend on the presence of clinical sleep complaints. In 2 population-representative case-control studies including 21,438 and 22,040 insomniacs, which were followed up over 4 or 10 years, respectively $(1,545$ and 1,049 incident strokes), physician-diagnosed insomnia predicted stroke after adjustment for age, sex, vascular risk factors, depression, anxiety, and socioeconomic status (HR 1.54; 1.38-1.72 and 1.85; 1.622.12). ${ }^{29,30}$ In a Swedish population-based cohort of 41,192 participants followed up over 13.2 years (4,031 vascular events, including 1,685 incident strokes), short sleep, defined as $\leq 5$ hours sleep/ night, predicted cardiovascular events when associated with difficulty falling asleep, difficulty maintaining sleep, early morning awakening, or nonrestorative sleep, but not when not associated with these complaints. ${ }^{31}$ Possible reasons for the elevated stroke risk may include chronic stress. 
RLS/PLMS. After inconsistent findings from crosssectional studies regarding the association of RLS with stroke and coronary heart disease (CHD), longitudinal studies in population-based cohorts and health professionals reported that RLS at baseline predicts incident CHD and death, ${ }^{32}$ but not stroke, ${ }^{33,34}$ in addition to age, sex, and vascular risk factors. In the 2 stroke studies, ${ }^{33,34} 54,558$ participants were followed up over 2.1-7.3 years (673 incident strokes).

In 2 population-representative cohorts including 5,620 and 7,392 participants who were followed up over up to 8.1 years, vascular risk factors, namely arterial hypertension, diabetes, hypercholesterolemia, and BMI, predicted incident RLS. ${ }^{34,35}$ In the larger of these studies, incident RLS predicted incident stroke, which in this study was noted in 397 participants. ${ }^{35}$ The combined evidence of these studies is still insufficient for justifying final conclusions about mutual links between RLS and stroke.

In 1,093 patients with end-stage renal disease, which carries a particularly high vascular risk, RLS predicted stroke over a 3.7-year follow-up after adjustment for age, sex, and vascular risk factors (HR 2.64; 1.49-4.91). ${ }^{36}$ It has been suggested that RLS consequences depend on the duration of RLS complaints. In the largest CHD study, comprising 70,977 participants with 5.6 years of follow-up, RLS predicted CHD when RLS complaints persisted for $\geq 3$ years. ${ }^{32}$ RLS-associated PLMS are accompanied by short-lasting elevations of blood pressure and sympathetic hyperactivity. ${ }^{2}$ Whether these autonomic responses are able to induce arterial hypertension remains to be shown.

DISTURBED SLEEP AND STROKE RECOVERY AND OUTCOME Sleep-disordered breathing. In a systematic review, 10 studies including 1,203 stroke and TIA patients were identified, in which effects of SDB on stroke outcome, i.e., death and recurrent vascular events, were analyzed. ${ }^{37}$ All studies reported elevated risks for death or vascular events, respectively. Most studies had follow-ups $\leq 2$ years. Only 2 studies evaluating cohorts of 132 and 166 patients with 10 or 7 years follow-up (116 and 89 deaths, respectively) were truly powered for multivariable regression analyses. In these studies, OSA, defined by AHI $\geq 15 / \mathrm{h}$ or $\mathrm{AHI} \geq 20 / \mathrm{h}$, predicted death (HR 1.76 ; $1.05-2.95$ ) or nonfatal cardiovascular events (namely recurrent stroke) (HR 1.76; 1.12-2.68) in addition to age, sex, vascular risk factors, and Barthel Index. Earlier smaller studies reported that SDB negatively affects poststroke arterial blood pressure, early neurologic recovery, and hospitalization duration. ${ }^{2}$ These studies were not powered for multivariable analyses.
Hypersomnia/excessive sleep/EDS. Hypersomnia/EDS impairs stroke recovery, as shown in a cohort of 213 stroke patients admitted to an acute rehabilitation unit, in which hypersomnia detected by rehabilitation therapists predicted disability and nursing home referral at discharge. ${ }^{38}$ In a nationwide register of 8,194 stroke patients, the presence of fatigue 2 years poststroke was associated with nursing home referral and predicted mortality in the following year (297 deaths) after adjustment for age, sex, stroke type, and activities of daily living. ${ }^{39}$ This study did not adjust for medical conditions unrelated to the stroke (e.g., infections, cardiovascular diseases).

Insomnia/reduced sleep. In acute stroke patients, insomnia assessed by questionnaires was associated with poor life satisfaction in addition to depression and severe stroke. ${ }^{2}$

In experimental stroke models, sleep loss/deprivation was found to augment brain injury and impair neuroplasticity, ${ }^{40}$ whereas drugs that promote NREM and REM sleep had a favorable effect on neuroplasticity and stroke recovery. ${ }^{41}$ In 13 chronic stroke patients, imitation-based speech therapy increased slow wave activity (SWA) during sleep evaluated by highdensity EEG ${ }^{42}$ SWA in speech-related areas correlated closely with improvements of aphasia scores. ${ }^{42}$ These data argue in favor of a sustained role of NREM sleep in stroke recovery.

RLS/PLMS. In 96 acute stroke patients followed up over 1 year, patients with RLS (12.5\%) had a higher neck circumference, poorer sleep quality, and higher diabetes prevalence than patients without RLS. ${ }^{14}$ Stroke recovery evaluated by the modified Rankin Scale and Barthel Index was worse in RLS than non-RLS patients after adjustment for diabetes and BMI. Due to the limited size of this study, other risk factors could not be adjusted for.

\section{DIAGNOSIS AND THERAPY Sleep-disordered breathing.} SDB can be accurately diagnosed in stroke patients by respiratory polygraphy, in which nasal airflow, respiratory movements, and capillary oxygen saturation are monitored. More simple but less accurate screening methods are oximetry or nasal airflow measurement, which can be combined with SDB questionnaires (e.g., Berlin questionnaire). CPAP is the treatment of choice for OSA. In patients with CSA/CSB, oxygen, biphasic positive airway pressure, or adaptive servoventilation may be considered. Mechanical ventilation and rarely tracheostomy may become necessary in patients with central hypoventilation.

Eight randomized studies investigated effects of CPAP poststroke (table 1), ${ }^{43-51}$ of which $5^{45,48-51}$ were initiated in the acute stroke phase, i.e., the first week poststroke. Most studies noted acceptable CPAP 
Table 1 Effects of continuous positive airway pressure (CPAP) and other therapies for sleep-disordered breathing (SDB) poststroke

$\begin{array}{lll}\text { Study } & \text { Type } & \text { Patients } \\ \begin{array}{l}\text { Sandberg } \\ \text { et al. }{ }^{43}\end{array} & \begin{array}{l}\text { Randomized single- } \\ \text { blind study }\end{array} & \begin{array}{l}63 \text { ischemic stroke patients with } \\ \text { respiratory disturbance index } \geq 15 / \mathrm{h} \\ \text { recruited in a rehabilitation unit at } 2-4 \\ \text { weeks poststroke; randomization to CPAP } \\ \text { or no CPAP over } 28 \text { days }\end{array} \\ & \end{array}$

Hsu et al. $^{44}$ Randomized singleblind study (blind assessment of outcomes)

30 stroke patients with $\mathrm{AHI} \geq 30 / \mathrm{h}$ recruited at 21-25 days poststroke; randomization to CPAP or no CPAP over 8 weeks $\begin{array}{ll}\text { Bravata } & \text { Randomized single- } \\ \text { et al. }{ }^{45} & \text { blind study }\end{array}$

$\begin{array}{ll}\text { Svatikova } & \begin{array}{l}\text { Randomized single- } \\ \text { et al. }\end{array} \\ & \begin{array}{l}\text { blind cross-over }^{26} \\ \text { study }\end{array}\end{array}$

Ryan et al. ${ }^{47}$ Randomized singleblind study (blind assessment of outcomes)

$\begin{array}{ll}\text { Age, } y & \mathrm{BMI}, \mathrm{kg} / \mathrm{m}^{2} \\ 77 \pm 8 \text { (no } & 25 \pm 5 \text { (no } \\ \text { CPAP), 78 } \pm 6 & \text { CPAP), 24 } \pm 4 \\ \text { (CPAP) } & \text { (CPAP) }\end{array}$

Median 73 (Q1, Q3: 73, 81) (no CPAP), 74 (Q1, Q3: 65, 77) (CPAP)
Median 25 (Q1, Q3: 21, 29) (no CPAP), 27 (Q1, Q3: 22, 33) (CPAP)
70 TIA patients randomized within 72 hours post-TIA; patients with $A H I \geq 5 / h$ received CPAP or no CPAP over 90 days; 12 patients (no CPAP) vs 30 patients (CPAP) completed study
In first study phase, 18 ischemic stroke patients with $\mathrm{AHI}>5 / \mathrm{h}$ randomized to positional therapy (therapeutic pillow) or no positional therapy (regular pillow) within 14 days poststroke; treatment administered during 2 consecutive nights in crossover design; in second study phase, same 18 patients randomized to positional therapy or no positional therapy for 3 months
Median 58 (Q1, Median 29 (Q1, Q3: 54,68$) \quad$ Q3: 28,33

Findings

CPAP was used by 31 out of 33 patients for 4 weeks; mean CPAP use was $4.1 \pm 3.6 \mathrm{~h} /$ night CPAP treatment improved depressive symptoms, but did not significantly change MMSE score or Barthel index; low cognitive level (MMSE score) predicted poor CPAP use

Mean CPAP use was poor (1.4 h/night); the study was prematurely stopped due to poor recruitment; CPAP treatment did not influence neurologic outcome, anxiety, depression, or quality of life; no significant difference in 24-hour daytime and nighttime systolic, diastolic, and mean arterial blood pressure between groups; 7 of 15 patients $(47 \%)$ kept using the CPAP device over more than 4 weeks; treatment discontinued in 8 patients because of problems with mask or machine, stroke-related confusional states, or upper airway symptoms; CPAP use positively correlated with good Barthel Index and good language capabilities

Forty percent of SDB patients had acceptable ( $\geq 4 \mathrm{~h} /$ night) and $60 \%$ some ( $<4$ h/night) CPAP use; 3 CPAP patients and 1 control patient had recurrent vascular events; there was a nonsignificant tendency towards a lower event rate in patients with acceptable $(0 \%)$ compared with some $(6 \%)$ CPAP use $(p=0.08)$

In within-participant comparison (first phase), positional therapy reduced $\mathrm{AHI}$ from median $39 / \mathrm{h}(21 / \mathrm{h}, 54 / \mathrm{h})$ to $27 / \mathrm{h}(22 / \mathrm{h}, 47 / \mathrm{h})$ therapeutic pillow reduced time supine from median $142(31,295)$ to $30(3,66)$ minutes: median and minimum oxygen saturation remained unchanged; in second phase (between- participant comparison), selfreported adherence was 3 (33\%) all nights, 1 $(11 \%)$ most nights, 2 (22\%) some nights, and $3(33 \%)$ no nights in participants randomized to positional therapy; of those randomized to the therapeutic pillow, 7 (78\%) had a good outcome, while $6(67 \%)$ of those not randomized to the pillow had a good outcome

44 stroke patients with $\mathrm{AHI}>15 / \mathrm{h}$ recruited within 3 weeks poststroke; randomization to CPAP or no CPAP over 4 weeks

$29 \pm 5$ (no

CPAP), $63 \pm 13 \quad$ CPAP) $27 \pm 6$ (CPAP) (CPAP)

Mean CPAP use was $5.0 \pm 2.3 \mathrm{~h} /$ night; regarding primary outcomes, $\mathrm{CPAP}$ treatment improved neurologic deficits evaluated by Canadian Neurologic Scale, but not 6-minute walk distance, sustained attention response, and digit and visual spatial span; regarding secondary outcomes, CPAP improved sleepiness evaluated by Epworth Sleepiness Scale, motor component of the functional independence measure Chedoke-McMaster lower leg function, and affective component of depression

A total of $62.5 \%$ of SDB patients had acceptable ( $\geq 4 \mathrm{~h} /$ night) and $37.5 \%$ some $(<4$ h/night) CPAP use; NIH Stroke Scale improved more in CPAP $(-3.0)$ than control $(-1.0)$ patients $(p=0.03) ; 1$ CPAP patient and 3 control patients had recurrent vascular events; event rate did not differ between groups $\mathrm{AHI} \geq 5 / \mathrm{h}$ received CPAP or no CPAP over 30 days; 15 patients (no CPAP) vs 16 patients (CPAP) completed study

(CPAP)

(CPAP)

Of 71 patients randomized to CPAP, 14

$66 \pm 9$ (no $29 \pm 4$ (no

(PAP), $64 \pm 9 \quad$ CPAP), $30 \pm 5$

(CPAP)

(CPAP) rused participation after 1-3 nights and 6 additional patients refused continuation after a mean of 10 months; in the others, mean CPAP use was $5.3 \pm 1.9 \mathrm{~h} /$ night; percentage of patients exhibiting improvement in Canadian neurologic scale and Rankin scale 1 month after stroke was significantly higher in patients receiving CPAP than controls; mean values in Canadian Neurologic Scale and Rankin scale did not differ between groups at any timepoint; in log rank tests, CPAP increased cardiovascular survival (100\% vs $89.9 \% ; p=0.02)$; there was a nonsignificant tendency towards increased cardiovascular event-free survival in CPAP compared with control patients $(89.5 \%$ vs $75.4 \% ; p=0.06$ ) 
Table 1 Continued

\begin{tabular}{|c|c|c|c|c|c|}
\hline Study & Type & Patients & Age, y & BMI, $\mathrm{kg} / \mathrm{m}^{2}$ & Findings \\
\hline $\begin{array}{l}\text { Minnerup } \\
\text { et al. }\end{array}$ & $\begin{array}{l}\text { Randomized single- } \\
\text { blind study (blind } \\
\text { assessment of } \\
\text { outcomes) }\end{array}$ & $\begin{array}{l}50 \text { ischemic stroke patients with } \mathrm{AHI} \\
>10 / \mathrm{h} \text { recruited within } 1 \text { st night } \\
\text { poststroke; randomization to CPAP } \\
\text { or no CPAP over } 7 \text { days }\end{array}$ & $\begin{array}{l}63 \pm 11 \text { (no } \\
\text { CPAP), } 69 \pm 10 \\
\text { (CPAP) }\end{array}$ & $\begin{array}{l}27 \pm 3 \text { (no } \\
\text { CPAP), } 28 \pm 3 \\
(C P A P)\end{array}$ & $\begin{array}{l}\text { Forty percent of SDB patients had } \\
\text { acceptable ( } \geq 4 \mathrm{~h} / \mathrm{night}), 56 \% \text { some } \\
(<4 \mathrm{~h} / \text { night), and } 4 \% \text { no CPAP use; patients } \\
\text { receiving CPAP revealed a nonsignificant } \\
\text { tendency towards a better NIH Stroke } \\
\text { Scale improvement }(-2.0) \text { compared with } \\
\text { control patients }(-1.4 ; p=0.09)\end{array}$ \\
\hline $\begin{array}{l}\text { Brown } \\
\text { et al. }\end{array}$ & $\begin{array}{l}\text { Randomized double- } \\
\text { blind study }\end{array}$ & $\begin{array}{l}32 \text { ischemic stroke patients with } \mathrm{AHI} \\
\geq 5 / \mathrm{h} \text { recruited within } 7 \text { days poststroke; } \\
\text { randomization to CPAP or sham CPAP } \\
\text { over } 90 \text { days }\end{array}$ & $\begin{array}{l}\text { Median } 74 \text { (Q1, } \\
\text { Q3: } 55,81 \text { ) } \\
\text { (sham CPAP), } 61 \\
(46,76) \text { (CPAP) }\end{array}$ & $\begin{array}{l}\text { Median } 29 \text { (Q1, } \\
\text { Q3: 28, 32) } \\
\text { (sham CPAP), } 28 \\
(23,31)(C P A P)\end{array}$ & $\begin{array}{l}\text { Of } 15 \text { patients who commenced active } \\
\text { CPAP titration, } 11 \text { ( } 73 \%) \text { took the device } \\
\text { home and } 8(53 \%) \text { completed the } 90 \text {-day } \\
\text { follow-up; of } 17 \text { participants who } \\
\text { commenced sham titration, } 11 \text { ( } 65 \% \text { ) took } \\
\text { the sham device home and completed the } \\
90 \text {-day follow-up; cumulative usage was } \\
\text { poor (mean } 0.8 \mathrm{~h} / \text { night for sham CPAP; } 0.6 \\
\text { h/night for CPAP); average usage on days } \\
\text { used was } 3.5(1.8,4.1) \text { h/night for sham } \\
\text { CPAP, } 4.5(2.6,5.5) \text { h/night for CPAP; } 50 \% \\
\text { of patients receiving CPAP and O\% of } \\
\text { patients receiving sham CPAP felt more } \\
\text { awake during the day; stroke outcome } \\
\text { evaluated by Barthel Index, Rankin scale, } \\
\text { and NIH Stroke Scale remained unchanged }\end{array}$ \\
\hline
\end{tabular}

Abbreviations: $\mathrm{AHI}=$ apnea-hypopnea index; $\mathrm{BMI}=$ body mass index; MMSE = Mini-Mental State Examination.

If not otherwise mentioned, data are mean \pm SD.

adherence ( $\geq 4 \mathrm{~h} /$ night) in more than half of the patients. ${ }^{43,45,47-50}$ Two studies (one acute, one postacute) reported poor CPAP use (0.6-1.4 h/night). ${ }^{44,51}$ Seven studies used no CPAP as control condition. ${ }^{43-45,47-50}$ One study used sham CPAP; this study was truly double-blind..$^{51}$ Despite the small study size (a total of 484 patients were included), 4 of 8 studies reported favorable CPAP effects, namely significant improvements in neurologic recovery, ${ }^{47,48}$ sleepiness, ${ }^{47}$ depression, ${ }^{43,47}$ and recurrent vascular events. ${ }^{49}$ One study found a nonsignificant tendency towards better neurologic improvement in patients receiving CPAP. ${ }^{50}$ The 3 remaining studies reported no significant outcome changes, but beneficial associations of CPAP use with at least some aspects of daytime wakefulness, ${ }^{51}$ neurologic recovery, ${ }^{44}$ or low recurrent vascular event rates. ${ }^{45}$

These findings contrast with the multitude of negative pharmacologic stroke studies. However, some CPAP studies were designed as feasibility studies. These studies were not powered for demonstrating outcome changes. In several studies, primary outcomes were not predefined. Larger multicenter studies with predefined outcomes, e.g., Sleep Disordered Breathing in Transient Ischemic Attack (TIA)/Ischemic Stroke and Continuous Positive Airway Pressure (CPAP) Treatment Efficacy (SAS-CARE) (https://www.clinicaltrials.gov/ ct2/show/NCT01097967), are ongoing. Their results are eagerly awaited.

A small percentage of stroke patients worldwide receive CPAP treatment. Yet the American Heart Association recently included recommendations on diagnosis and treatment of SDB, stating that (1) a sleep study might be considered for patients with ischemic stroke or TIA on the basis of the very high prevalence of sleep apnea in this population and (2) CPAP treatment might be considered for patients with ischemic stroke and TIA and sleep apnea, given the emerging evidence in support of improved outcomes (Class IIb evidence, B recommendation). ${ }^{52}$

In a crossover study on 18 ischemic stroke patients with $\mathrm{AHI}>5 / \mathrm{h}$ randomized to positional therapy (therapeutic pillow) or no positional therapy within 14 days poststroke, positional therapy reduced $\mathrm{AHI}^{46}$ (Class III evidence; tables 1 and 2). Median and minimum oxygen saturation remained unchanged.

In an observation study on 10 ischemic stroke patients with $\mathrm{AHI}>15 / \mathrm{h}$ not eligible for CPAP at $4.8 \pm 3.7$ days poststroke, transnasal insufflation with high-flow air $(18 \mathrm{~L} / \mathrm{min})$ moderately reduced AHI from $40.7 / \mathrm{h}$ to $31.0 / \mathrm{h}$ and increased slow wave sleep. ${ }^{53}$ In 15 ischemic stroke patients with predominant CSA not adherent to CPAP at 11 months poststroke, adaptive servoventilation reduced EDS. ${ }^{54}$ Until further studies become available, adaptive servoventilation should be used with caution, since increased mortality has been reported during adaptive servoventilation in SDB patients with systolic heart failure. ${ }^{55}$

Weight loss should improve SDB, but was not systematically examined. Patient handling should always include prevention and therapy of secondary complications (respiratory infections, pain) and cautious use of alcohol and sedative-hypnotic drugs, which negatively affect breathing during sleep. In stroke patients with SDB, severe motor deficits (specifically facial/ bulbar palsy), cognitive deficits, aphasia, and depression may represent factors compromising CPAP compliance. $^{56}$ 
Hypersomnia/excessive sleep/EDS. With the exception of very severe cases, hypersomnia is often unrecognized in clinical practice. Actigraphy allows to detect changes of sleep/rest needs in stroke patients, ${ }^{10}$ but may have limited use in patients with severe motor deficits. Sleep questionnaires (e.g., Epworth Sleepiness Scale, Fatigue Severity Scale), which evaluate EDS and fatigue, may underestimate SWD in stroke patients with disturbed selfperception or communication skills. Polysomnography, multiple sleep latency tests, and maintenance of wakefulness tests are reserved for selected cases. The correlation of poststroke SWD and sleep EEG is limited when brain damage includes thalamocortical networks. ${ }^{11}$ Polysomnography typically reveals a reduction, less commonly an increase of NREM or REM sleep.
Treatment of poststroke hypersomnia/EDS is challenging (table 2). In patients with paramedian thalamic stroke, improvement of sleep patterns was reported with $20-40 \mathrm{mg}$ bromocriptine, $200 \mathrm{mg}$ modafinil, or 20-50 mg methylphenidate (Class IV evidence). ${ }^{10} \mathrm{~A}$ favorable effect on early stroke recovery was observed after levodopa $(100 \mathrm{mg} / \mathrm{d})$ or methylphenidate $(5-30 \mathrm{mg} / \mathrm{d})$, which may at least partly be related to improved wakefulness. ${ }^{2}$ Stimulating antidepressants may also improve hypersomnia. Whether treatment of hypersomnia, EDS, or fatigue improves stroke outcome and recurrent risk needs to be shown.

Insomnia/reduced sleep. The presence of insomnia is often overlooked in clinical practice. Questionnaires and actigraphy can be useful to recognize insomnia,

\begin{tabular}{|c|c|c|c|c|}
\hline Diagnostics & ind treatment of sleep-relat & ed breathing and sleep-wake & isorders following stroke & \\
\hline Sleep-wake disorder & Diagnostics & Avoid/use with cautions & Treatment & $\begin{array}{l}\text { Level of evidencel } \\
\text { recommendation }\end{array}$ \\
\hline \multirow[t]{4}{*}{$\begin{array}{l}\text { Obstructive } \\
\text { sleep apnea }\end{array}$} & $\begin{array}{l}\text { History, respirography } \\
\text { (polysomnography) }\end{array}$ & $\begin{array}{l}\text { Alcohol, hypnotics, sedative } \\
\text { antidepressants }\end{array}$ & CPAP & Illb, B \\
\hline & & & Transnasal high-flow air insufflation & IV, U \\
\hline & & & $\begin{array}{l}\text { Preventing supine sleeping position } \\
\text { with therapeutic pillow }\end{array}$ & III, $\mathrm{C}^{\mathrm{a}}$ \\
\hline & & & Weight loss & IV, U \\
\hline \multirow[t]{4}{*}{$\begin{array}{l}\text { Central sleep apnea/ } \\
\text { Cheyne-Stokes breathing }\end{array}$} & $\begin{array}{l}\text { History, respirography } \\
\text { (polysomnography) }\end{array}$ & $\begin{array}{l}\text { Alcohol, hypnotics, sedative } \\
\text { antidepressants }\end{array}$ & CPAP/biphasic positive airway pressure & IV, U \\
\hline & & & Adaptive servoventilation & IV, U \\
\hline & & & Oxygen & IV, U \\
\hline & & & $\begin{array}{l}\text { Tracheotomy/mechanical ventilation } \\
\text { in severe central apnea }\end{array}$ & $\mathrm{IV}, \mathrm{U}$ \\
\hline \multirow[t]{3}{*}{$\begin{array}{l}\text { Disturbances of } \\
\text { wakefulness } \\
\text { (hypersomnia, EDS, } \\
\text { fatigue) }\end{array}$} & $\begin{array}{l}\text { History, questionnaires } \\
\text { (actigraphy, } \\
\text { polysomnography, vigilance } \\
\text { tests) }\end{array}$ & $\begin{array}{l}\text { Alcohol, hypnotics, sedative } \\
\text { antidepressants }\end{array}$ & $\begin{array}{l}\text { Stimulating antidepressants (e.g., } \\
\text { venlafaxine } 37.5-150 \mathrm{mg} / \mathrm{d} \text { ) }\end{array}$ & IV, U \\
\hline & & & $\begin{array}{l}\text { Simulants: modafinil }(100-200 \mathrm{mg} / \mathrm{d}) \text {, } \\
\text { methylphenidate }(5-60 \mathrm{mg} / \mathrm{d})\end{array}$ & IV, U \\
\hline & & & Levodopa (125-250 mg/d) & IV, U \\
\hline \multirow[t]{3}{*}{ Insomnia } & $\begin{array}{l}\text { History (questionnaires, } \\
\text { actigraphy, polysomnography) }\end{array}$ & $\begin{array}{l}\text { Alcohol, caffeine, stimulating } \\
\text { antidepressants }\end{array}$ & Zolpidem, zopiclone & $\mathrm{IV}, \mathrm{U}^{\mathrm{b}}$ \\
\hline & & & $\begin{array}{l}\text { Sedative antidepressants (amitriptyline } \\
10-100 \mathrm{mg} / \mathrm{d} ; \text { trazodone } 50-200 \mathrm{mg} / \mathrm{d} ; \\
\text { mianserin } 60 \mathrm{mg} / \mathrm{d} \text {; mirtazapine } \\
15-30 \mathrm{mg} / \mathrm{d} \text { ) }\end{array}$ & IV, U (mianserin: III, C \\
\hline & & & $\begin{array}{l}\text { Nonpharmacologic sleep hygiene (avoid } \\
\text { noises, treat infections, avoid alcohol and } \\
\text { caffeine at night) }\end{array}$ & $\mathrm{IV}, \mathrm{U}$ \\
\hline \multirow[t]{3}{*}{$\begin{array}{l}\text { Restless legs syndrome/ } \\
\text { periodic limb movements } \\
\text { during sleep }\end{array}$} & History, polysomnography & $\begin{array}{l}\text { Antidepressants, neuroleptics, } \\
\text { metoclopramide, lithium }\end{array}$ & Levodopa (125-250 mg at night) & $\mathrm{IV}, \mathrm{U}$ \\
\hline & & & $\begin{array}{l}\text { Dopamine agonists (ropinirole } 0.25-1 \\
\mathrm{mg} / \mathrm{d} \text {, pramipexole } 0.125-0.75 \mathrm{~g} / \mathrm{d} \text { ) }\end{array}$ & III, U \\
\hline & & & Gabapentin (150-300 mg/d) & IV, U \\
\hline $\begin{array}{l}\text { REM sleep } \\
\text { behavior disorder }\end{array}$ & History, polysomnography & $\begin{array}{l}\text { Alcohol, antidepressants } \\
\text { (serotonin reuptake inhibitors), } \\
\text { stimulants, selegiline }\end{array}$ & Clonazepam (0.5-2 mg at night) & IV, U \\
\hline
\end{tabular}

Abbreviations: CPAP = continuous positive airway pressure; EDS = excessive daytime sleepiness.

Recommendations based on American Academy of Neurology classification of recommendation. Only studies in stroke patients were considered.

a Refers to effects on apnea-hypopnea index or sleep, not stroke outcome.

${ }^{\mathrm{b}}$ Beneficial effect on stroke outcome and recurrent stroke risk unlikely. 
but may underestimate SWD (see above). Polysomnography is mainly used for detecting secondary insomnias (e.g., related to SDB or RLS/PLMS).

Treatment of poststroke insomnia includes placement of patients in quiet rooms at night, protection from noise and light, light exposure and physical activity during the day, and, where necessary, temporary use of hypnotics that are relatively free of cognitive and muscle-relaxant effects, such as zolpidem, which in a small study of 12 stroke patients had similar effects on total sleep time and sleep quality as lorazepam ${ }^{2}$ and may have beneficial effects on stroke recovery based on experimental stroke studies. ${ }^{57} \mathrm{Ben}-$ zodiazepines may worsen SDB and neuropsychological deficits and lead to reemergence of motor deficits (table 2). Sedative antidepressants may improve poststroke insomnia (table 2). In 51 stroke patients, 60 $\mathrm{mg} / \mathrm{d}$ mianserin improved insomnia, also in patients without depression (Class III evidence). ${ }^{2}$

In case-control studies, hypnotics elevated stroke risk. In 12,747 ischemic stroke patients matched with participants without stroke, zolpidem use was dose-dependently associated with ischemic stroke risk (OR 1.50 for $>470 \mathrm{mg}$ zolpidem/y)..$^{58}$ In a cohort of 38,671 patients on benzodiazepines matched with patients without benzodiazepines, a high annual benzodiazepine dose ( $\geq 4 \mathrm{~g}$ ) or long duration of benzodiazepine use ( $\geq 95$ days) increased stroke incidence. ${ }^{59}$ Further studies are needed to delineate effects of hypnotics on stroke recovery and recurrence.

RLS/PLMS. RLS is a clinical diagnosis, while PLMS diagnosis requires polysomnography. RLS symptoms are often not perceived by stroke patients.

Patients with stroke-related RLS/PLMS can be treated with dopamine agonists (ropinirole $0.25-1$ $\mathrm{mg} / \mathrm{d}$, pramipexole $0.125-0.5 \mathrm{mg} / \mathrm{d}$ ) or gabapentin (150-300 mg/d) (table 2). Using dopamine agonists, Lee et al. ${ }^{13}$ reported marked relief in almost all patients. Spontaneous improvement was noted in approximately 1 of 4 patients. ${ }^{13}$ Antidepressants, neuroleptics, metoclopramide, and lithium should be avoided wherever possible, because they may aggravate RLS/PLMS. Whether RLS/PLMS treatment influences stroke outcome or recurrence needs to be shown.

REM sleep behavior disorder. RBD can be suspected on clinical grounds but diagnosis requires videopolysomnography. Clonazepam at bedtime efficiently improves RBD. Although Class IV evidence, stroke patients with RBD may receive clonazepam (0.5$2.0 \mathrm{mg}$ ) (table 2). Alcohol, serotonin reuptake inhibitors, stimulants, and selegiline aggravate RBD. They should be avoided in RBD.
FUTURE DIRECTIONS AND RECOMMENDATIONS Systematic approaches for the diagnosis and treatment of SDB and SWD should be implemented in the management of stroke and TIA. Oximetry or nasal flow measurement can suggest SDB, which should be confirmed by respirography before treatment. Careful patient histories, questionnaires, and actigraphies improve the detection of SWD. Treatment is relevant for stroke recovery and outcome, but should be used thoughtfully considering potential side effects.

\section{AUTHOR CONTRIBUTIONS}

D.M.H., C.L.B.: study concept and design, acquisition of data and articles, analysis and interpretation, critical revision of the manuscript for important intellectual content, study supervision. D.M.H.: drafting of manuscript.

\section{STUDY FUNDING}

No targeted funding reported.

\section{DISCLOSURE}

The authors report no disclosures relevant to the manuscript. Go to Neurology.org for full disclosures.

Received December 27, 2015. Accepted in final form June 9, 2016.

\section{REFERENCES}

1. Bassetti CL, Ferini-Strambi L, Brown S, et al. Neurology and psychiatry: waking up to opportunities of sleep: state of the art and clinical/research priorities for the next decade. Eur J Neurol 2015;22:1337-1354.

2. Hermann DM, Bassetti CL. Sleep-related breathing and sleep-wake disturbances in ischemic stroke. Neurology 2009;73:1313-1322.

3. Johnson KG, Johnson DC. Frequency of sleep apnea in stroke and TIA patients: a meta-analysis. J Clin Sleep Med 2010;6:131-137.

4. Ciccone A, Proserpio P, Roccatagliata DV, et al. Wake-up stroke and TIA due to paradoxical embolism during long obstructive sleep apneas: a cross-sectional study. Thorax 2013;68:97-104.

5. Brown DL, McDermott M, Mowla A, et al. Brainstem infarction and sleep-disordered breathing in the BASIC sleep apnea study. Sleep Med 2014;15:887-891.

6. Manconi M, Zavalko I, Cereda C, et al. Longitudinal polysomnographic assessment from acute to subacute phase in infratentorial versus supratentorial stroke. Cerebrovasc Dis 2014;37:85-93.

7. Bassetti CL, Milanova M, Gugger M. Sleep-disordered breathing and acute ischemic stroke: diagnosis, risk factors, treatment, evolution, and long-term clinical outcome. Stroke 2006;37:967-972.

8. Yumino D, Redolfi S, Ruttanaumpawan P, et al. Nocturnal rostral fluid shift: a unifying concept for the pathogenesis of obstructive and central sleep apnea in men with heart failure. Circulation 2010;121:1598-1605.

9. Nopmaneejumruslers C, Kaneko Y, Hajek V, et al. Cheyne-Stokes respiration in stroke: relationship to hypocapnia and occult cardiac dysfunction. Am J Respir Crit Care Med 2005;171:1048-1052.

10. Bassetti C, Mathis J, Gugger M, et al. Hypersomnia following thalamic stroke: a report of 12 patients. Ann Neurol 1996;39:471-480. 
11. Hermann DM, Siccoli MM, Brugger P, et al. Evolution of neurological, neuropsychological and sleep-wake disturbances in paramedian thalamic stroke. Stroke 2008;39:62-68.

12. Koenigs M, Holliday J, Solomon J, Grafman J. Left dorsomedial frontal brain damage is associated with insomnia. J Neurosci 2010;30:16041-16043.

13. Lee SJ, Kim JS, Song IU, et al. Poststroke restless legs syndrome and lesion location: anatomical considerations. Mov Disord 2009;24:77-84.

14. Medeiros CA, de Bruin PF, Paiva TR, et al. Clinical outcome after acute ischaemic stroke: the influence of restless legs syndrome. Eur J Neurol 2011;18:144-149.

15. Benbir G, Karadeniz D. Periodic leg movements in sleep in patients with supratentorial cerebral infarction. Acta Neurol Belg 2012;112:27-32.

16. Tang WK, Hermann DM, Chen YK, et al. Brainstem infarcts predict REM sleep behavior disorder in acute ischemic stroke. BMC Neurol 2014;14:88.

17. Yaggi HK, Concato J, Kernan WN, et al. Obstructive sleep apnea as a risk factor for stroke and death. N Engl J Med 2005;353:2034-2041.

18. Arzt M, Young T, Finn L, et al. Association of sleepdisordered breathing and the occurrence of stroke. Am J Respir Crit Care Med 2005;172:1447-1451.

19. Munoz R, Duran-Cantolla J, Martinez-Vila E, et al. Severe sleep apnea and risk of ischemic stroke in the elderly. Stroke 2006;37:2317-2321.

20. Redline S, Yenokyan G, Gottlieb DJ, et al. Obstructive sleep apnea-hypopnea and incident stroke: the sleep heart health study. Am J Respir Crit Care Med 2010;182:269-277.

21. Lamberts M, Nielsen OW, Lip GY, et al. Cardiovascular risk in patients with sleep apnoea with or without continuous positive airway pressure therapy: follow-up of 4.5 million Danish adults. J Intern Med 2014;276:659-666.

22. Loke YK, Brown JW, Kwok CS, Niruban A, Myint PK. Association of obstructive sleep apnea with risk of serious cardiovascular events: a systematic review and meta-analysis. Circ Cardiovasc Qual Outcomes 2012;5:720-728.

23. Chang CC, Chuang HC, Lin CL, et al. High incidence of stroke in young women with sleep apnea syndrome. Sleep Med 2014;15:410-414.

24. Sánchez-de-la-Torre M, Campos-Rodriguez F, Barbé F. Obstructive sleep apnoea and cardiovascular disease. Lancet Respir Med 2013;1:61-72.

25. Leng Y, Cappuccio FP, Wainwright NW, et al. Sleep duration and risk of fatal and non-fatal stroke: a prospective study and meta-analysis. Neurology 2015;84:1072-1079.

26. Boden-Albala B, Roberts ET, Bazil C, et al. Daytime sleepiness and risk of stroke and vascular disease: findings from the Northern Manhattan Study (NOMAS). Circ Cardiovasc Qual Outcomes 2012;5:500-507.

27. Blachier M, Dauvilliers Y, Jaussent I, et al. Excessive daytime sleepiness and vascular events: the Three City Study. Ann Neurol 2012;71:661-667.

28. Ramos AR, Dong C, Rundek T, et al. Sleep duration is associated with white matter hyperintensity volume in older adults: the Northern Manhattan Study. J Sleep Res 2014;23:524-530.

29. Wu MP, Lin HJ, Weng SF, et al. Insomnia subtypes and the subsequent risks of stroke: report from a nationally representative cohort. Stroke 2014;45:1349-1354.

30. Hsu CY, Chen YT, Chen MH, et al. The association between insomnia and increased future cardiovascular events: a nation-wide population-based study. Psychosom Med 2015;77:743-751.
31. Westerlund A, Bellocco R, Sundström J, et al. Sleep characteristics and cardiovascular events in a large Swedish cohort. Eur J Epidemiol 2013;28:463-473.

32. Li Y, Walters AS, Chiuve SE, et al. Prospective study of restless legs syndrome and coronary heart disease among women. Circulation 2012;126:1689-1694.

33. Winter AC, Schürks M, Glynn RJ, et al. Restless legs syndrome and risk of incident cardiovascular disease in women and men: prospective cohort study. BMJ Open 2012;2:e000866.

34. Szentkirályi A, Völzke H, Hoffmann W, Happe S, Berger K. A time sequence analysis of the relationship between cardiovascular risk factors, vascular diseases and restless legs syndrome in the general population. J Sleep Res 2013;22:434-442.

35. Molnar MZ, Lu JL, Kalantar-Zadeh K, Kovesdy CP. Association of incident restless legs syndrome with outcomes in a large cohort of US veterans. J Sleep Res Epub 2015 Sep 17.

36. Lin $\mathrm{CH}, \mathrm{Sy} \mathrm{HN}$, Chang HW, et al. Restless legs syndrome is associated with cardio/cerebrovascular events and mortality in end-stage renal disease. Eur J Neurol 2015;22: 142-149.

37. Birkbak J, Clark AJ, Rod NH. The effect of sleep disordered breathing on the outcome of stroke and transient ischemic attack: a systematic review. J Clin Sleep Med 2014;10:103-108.

38. Harris AL, Elder J, Schiff ND, Victor JD, Goldfine AM. Post-stroke apathy and hypersomnia lead to worse outcomes from acute rehabilitation. Transl Stroke Res 2014;5:292-300.

39. Glader EL, Stegmayr B, Asplund K. Poststroke fatigue: a 2-year follow-up study of stroke patients in Sweden. Stroke 2002;33:1327-1333.

40. Zunzunegui C, Gao B, Cam E, Hodor A, Bassetti CL. Sleep disturbance impairs stroke recovery in the rat. Sleep 2011;34:1261-1269.

41. Hodor A, Palchykova S, Gao B, Bassetti CL. Baclofen and gamma-hydroxybutyrate differentially altered behavior, EEG activity and sleep in rats. Neuroscience 2015;284: 18-28.

42. Sarasso S, Määttä S, Ferrarelli F, et al. Plastic changes following imitation-based speech and language therapy for aphasia: a high-density sleep EEG study. Neurorehabil Neural Repair 2014;28:129-138.

43. Sandberg O, Franklin KA, Bucht G, et al. Nasal continuous positive airway pressure in stroke patients with sleep apnoea: a randomized treatment study. Eur Respir J 2001; 18:630-634.

44. Hsu CY, Vennelle M, Li HY, et al. Sleep-disordered breathing after stroke: a randomised controlled trial of continuous positive airway pressure. J Neurol Neurosurg Psychiatry 2006;77:1143-1149.

45. Bravata DM, Concato J, Fried T, et al. Auto-titrating continuous positive airway pressure for patients with acute transient ischemic attack: a randomized feasibility trial. Stroke 2010;41:1464-1470.

46. Svatikova A, Chervin RD, Wing JJ, et al. Positional therapy in ischemic stroke patients with obstructive sleep apnea. Sleep Med 2011;12:262-266.

47. Ryan CM, Bayley M, Green R, Murray BJ, Bradley TD. Influence of continuous positive airway pressure on outcomes of rehabilitation in stroke patients with obstructive sleep apnea. Stroke 2011;42:1062-1067. 
48. Bravata DM, Concato J, Fried T, et al. Continuous positive airway pressure: evaluation of a novel therapy for patients with acute ischemic stroke. Sleep 2011;34:1271-1277.

49. Parra O, Sánchez-Armengol A, Capote F, et al. Efficacy of continuous positive airway pressure treatment on 5-year survival in patients with ischaemic stroke and obstructive sleep apnea: a randomized controlled trial. J Sleep Res 2015;24:47-53.

50. Minnerup J, Ritter MA, Wersching H, et al. Continuous positive airway pressure ventilation for acute ischemic stroke: a randomized feasibility study. Stroke 2012;43:1137-1139.

51. Brown DL, Chervin RD, Kalbfleisch JD, et al. Sleep apnea treatment after stroke (SATS) trial: is it feasible? J Stroke Cerebrovasc Dis 2013;22:1216-1224.

52. Kernan WN, Ovbiagele B, Black HR, et al. Guidelines for the prevention of stroke in patients with stroke and transient ischemic attack: a guideline for healthcare professionals from the American Heart Association/American Stroke Association. Stroke 2014;45:2160-2236.

53. Haba-Rubio J, Andries D, Rey V, et al. Effect of transnasal insufflation on sleep disordered breathing in acute stroke: a preliminary study. Sleep Breath 2012;16:759-764.
54. Brill AK, Rösti R, Hefti JP, et al. Adaptive servoventilation as treatment of persistent central sleep apnea in post-acute ischemic stroke patients. Sleep Med 2014; 15:1309-1313.

55. Cowie MR, Woehrle H, Wegscheider K, et al. Adaptive servo-ventilation for central sleep apnea in systolic heart failure. N Engl J Med 2015;373:1095-1105.

56. Benbir G, Karadeniz D. A pilot study of the effects of non-invasive mechanical ventilation on the prognosis of ischemic cerebrovascular events in patients with obstructive sleep apnea syndrome. Neurol Sci 2012;33: 811-818.

57. Hiu T, Farzampour Z, Paz JT, et al. Enhanced phasic GABA inhibition during the repair phase of stroke: a novel therapeutic target. Brain 2016;139:468-480.

58. Huang WS, Tsai CH, Lin CC, et al. Relationship between zolpidem use and stroke risk: a Taiwanese populationbased case-control study. J Clin Psychiatry 2013;74: e433-e438.

59. Huang WS, Muo CH, Chang SN, et al. Benzodiazepine use and risk of stroke: a retrospective population-based cohort study. Psychiatry Clin Neurosci 2014;68:255-262. 


\section{Neurology}

Role of sleep-disordered breathing and sleep-wake disturbances for stroke and stroke recovery

Dirk M. Hermann and Claudio L. Bassetti

Neurology 2016;87;1407-1416 Published Online before print August 3, 2016

DOI 10.1212/WNL.0000000000003037

This information is current as of August 3, 2016

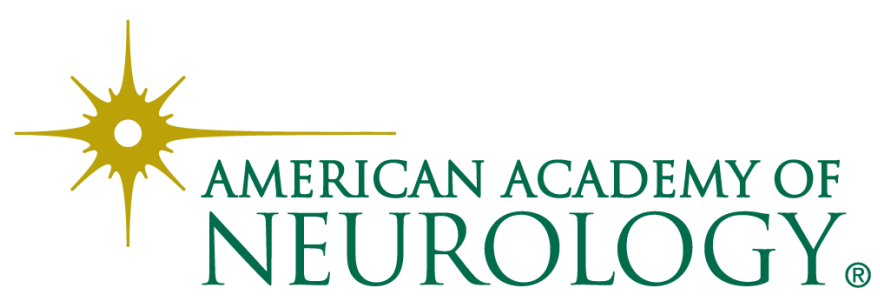




\section{Updated Information \& Services}

\section{Supplementary Material}

\section{References}

Citations

Subspecialty Collections

\section{Permissions \& Licensing}

\section{Reprints}

including high resolution figures, can be found at: http://n.neurology.org/content/87/13/1407.full

Supplementary material can be found at: http://n.neurology.org/content/suppl/2017/08/07/WNL.0000000000003 037.DC1

This article cites 58 articles, 20 of which you can access for free at: http://n.neurology.org/content/87/13/1407.full\#ref-list-1

This article has been cited by 4 HighWire-hosted articles: http://n.neurology.org/content/87/13/1407.full\#\#otherarticles

This article, along with others on similar topics, appears in the following collection(s):

\section{All Cerebrovascular disease/Stroke}

http://n.neurology.org/cgi/collection/all_cerebrovascular_disease_strok e

All Sleep Disorders

http://n.neurology.org/cgi/collection/all_sleep_disorders

Insomnia

http://n.neurology.org/cgi/collection/insomnia

Other hypersomnias

http://n.neurology.org/cgi/collection/other_hypersomnias

Sleep apnea

http://n.neurology.org/cgi/collection/sleep_apnea

Information about reproducing this article in parts (figures,tables) or in its entirety can be found online at:

http://www.neurology.org/about/about_the_journal\#permissions

Information about ordering reprints can be found online:

http://n.neurology.org/subscribers/advertise

Neurology ${ }^{\circledR}$ is the official journal of the American Academy of Neurology. Published continuously since 1951, it is now a weekly with 48 issues per year. Copyright (O 2016 American Academy of Neurology. All rights reserved. Print ISSN: 0028-3878. Online ISSN: 1526-632X.

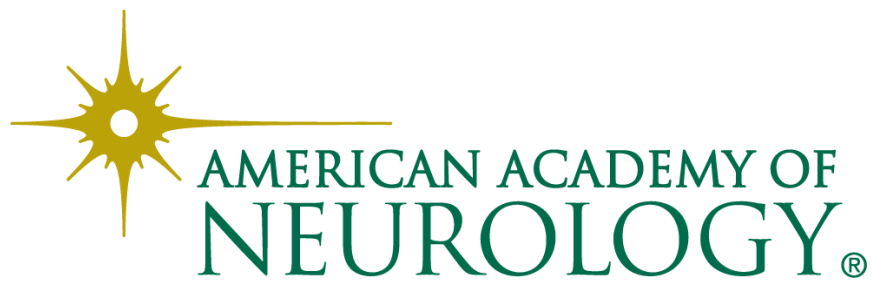

